\title{
DESENVOLVIMENTO DOS SERVIÇOS DE EMERGÊNCIA ESTADUAIS MEDIANTE APERFEIÇOAMENTO DOS FATORES DE DESEMPENHO NA CAPTAÇÃO DE RECURSOS FEDERAIS
}

\author{
Emmanuel de Oliveira Costa ${ }^{1}$ \\ José Luiz Alves ${ }^{2}$
}

\section{RESUMO}

Este artigo buscou evidenciar os fatores que influenciam os órgãos públicos estaduais na captação de recursos da União mediante transferências voluntárias. A temática surge em decorrência da necessidade de aperfeiçoar a gestão corporativa na busca de recursos mediante transferências voluntárias para aparelhar os serviços de emergência e resposta a desastres no Estado de Pernambuco. As dificuldades na elaboração de projetos de convênios, combinadas com as limitações para se conseguir orçamento da União por transferências intergovernamentais, desperta questionamentos sobre os elementos políticos, administrativos e educacionais que interferem na busca de transferências voluntárias e consequentes aportes financeiros federais pelos órgãos públicos estaduais. O método realizou a revisão e adaptação do Indicador de Desempenho na Captação de Transferências Voluntárias (IDCTV) ao contexto do Corpo de Bombeiros Militar de Pernambuco (CBMPE) servindo de mensuração do status quo da captação de recursos para aparelhar, modernizar e desenvolver os serviços de emergência estaduais.

Palavras Chave: Transferência Voluntária; Convênio Federal; Serviços de Emergência; Administração Pública.

\footnotetext{
${ }^{1}$ Mestre em Gestão do Desenvolvimento Local Sustentável pela Universidade de Pernambuco. Capitão do Corpo de Bombeiros Militar de Pernambuco. Email: emmanuel.oliveira@bombeiros.pe.gov.br

2 Economista e Doutor em Geografia pela Universidade Federal de Pernambuco (2011). Professor Adjunto no Programa de Pós Graduação em GDLS da Universidade de Pernambuco. Email: luiz.alves@upe.br
} 


\title{
DEVELOPMENT OF STATE EMERGENCY SERVICES BY IMPROVING PERFORMANCE FACTORS IN FEDERAL FUNDRAISING
}

\begin{abstract}
This article sought to highlight the factors that influence state public agencies in raising funds from the Union through voluntary transfers. The theme arises from the need to improve corporate management in the search for resources through voluntary transfers to equip emergency and disaster response services in the State of Pernambuco. The difficulties in the elaboration of agreement projects, combined with the limitations to obtain the Union's budget for intergovernmental transfers, raises questions about the political, administrative and educational elements that interfere in the search for voluntary transfers and consequent federal financial contributions by state public agencies. The method carried out the review and adaptation of the Performance Indicator for the Capture of Voluntary Transfers (IDCTV) to the context of the Pernambuco Military Fire Brigade (CBMPE), serving to measure the status quo of fundraising to equip, modernize and develop the services of state emergency services.
\end{abstract}

Key Words: Voluntary Transfer; Federal Agreement; Emergency Services; Public administration. 


\section{INTRODUÇÃO}

O Governo Federal utilizando o princípio da descentralização de suas políticas públicas regulamentou as transferências voluntárias (ou discricionárias) de recursos financeiros caracterizando-as como veículos para os repasses financeiros na execução de projetos e atividades de interesse comum da União e dos entes da administração direta e indireta dos Estados e Municípios. As Transferências Voluntárias do Governo Federal (TVGF) são uma das modalidades de repasse de recursos financeiros intergovernamentais entre a Federação e as entidades públicas subnacionais a título de cooperação, auxílio ou assistência financeira para o desenvolvimento de políticas públicas de resposta a emergências.

Destaca-se que os projetos técnicos exigidos para realização das TVGF devem ser submetidos à análise jurídica e técnica do Poder Executivo, inclusive os projetos públicos de orçamento oriundo de Emendas Parlamentares individuais (PEDERIVA; PEDERIVA, 2016).

Um fator crítico para o sucesso dos convênios federais, instrumentos que convertem políticas federais em ações públicas regionais, está em função da competência dos órgãos públicos em propor e executar projetos. Menciona-se que indicadores podem mensurar a complexidade sócio-administrativa dos órgãos públicos, ponderando a relevância de variáveis institucionais (GUIMARÃES, 2009), inclusive o desempenho da gestão na execução das TVGF. Dessa maneira, ressalta-se a aplicação de indicador de desempenho que mensure elementos de competências da pessoa jurídica de direito público na busca da qualidade da gestão (SANTOS; CARDOSO, 2001).

O desenvolvimento local promovido pela gestão governamental é, em grande parte, resultado do sucesso do planejamento das políticas públicas nacionais em consonância com a efetividade das execuções físicas e orçamentárias em níveis locais. Com objetivo de classificar e quantificar o 
Revista Científica do Corpo de Bombeiros Militar de Pernambuco

Artigo Publicado no Vol.06 N.17 - Edição Jul a Dez 2020 - ISSN 2359-4829

Versão on-line disponível em: http://www.revistaflammae.com

desempenho para o desenvolvimento, gestões públicas têm trabalhado com variáveis e indicadores na tentativa de promover melhor compreensão da realidade (OSTROVSKI; PASSOS, 2012).

\section{METODOLOGIA}

O método buscou fundamentação teórica sobre normas e aspectos técnicos dos instrumentos e procedimentos das transferências voluntárias, combinada com análise de informações dos portais públicos. Assim, a técnica da pesquisa bibliográfica analisou das informações por meio de discussão no campo teórico com base em livros e artigos nos bancos de dados da SciELO, Google Acadêmico, Portal da Capes, e a técnica da pesquisa documental analisou informações do Portal do Senado Federal, Portal da Câmara dos Deputados Federais e Portal da Controladoria Geral da União.

A pesquisa análise crítica do Indicador de Desempenho na Captação de Transferências Voluntárias do Governo Federal (IDCTV) com base nos elementos para o sucesso do Corpo de Bombeiros Militar de Pernambuco na captação de transferências voluntárias. A pesquisa empírica realizada na Diretoria de Planejamento e Gestão (DPLAG/CBMPE) alinhada com a pesquisa bibliográfica e documental foram direcionadas à fornecer embasamento para parametrizar as variáveis que contribuem no sucesso da captação de recursos.

\section{AS TRANSFERÊNCIAS INTERGOVERNAMENTAIS NO GOVERNO BRASILEIRO}

O fundamento apresentado por Gomes, Carmo e Scarpin (2012) sobre as transferências intergovernamentais é pautado em bases jurídicas e econômicas adequadas a sustentarem os repasses para o funcionamento de Estado federativo, já que os repasses financeiros entre as esferas de governos visam à manutenção da descentralização e desconcentração das atividades governamentais com vistas ao atendimento de objetivos genéricos e específicos da nação. 
Revista Científica do Corpo de Bombeiros Militar de Pernambuco

Artigo Publicado no Vol.06 N.17 - Edição Jul a Dez 2020 - ISSN 2359-4829

Versão on-line disponível em: http://www.revistaflammae.com

Duarte et al (2009) propuseram que as transferências intergovernamentais visam diminuir os desequilibrios entre as esferas de governo em perspectiva vertical de equilíbrio fiscal, além de perspectiva de distribuição horizontal de receitas e potencialidades tributários entre os entes federativos que possuem heterogeneidade ante a dimensão territorial do Brasil. Assim, as transferências governamentais são ferramentas federativas de gestão fiscal, legitimando mecanismos de distribuição de recursos e garantia de uniformidade de capacidade de prestação de serviços público (SAKURAI; THEODORO, 2014).

A construção de Estado Federativo necessariamente abrange a dialética sobre as responsabilidades do sistema de mecanismos legais e procedimentais de transferências de recursos entre as esferas de governo, ponderando a sustentabilidade do modelo de gestão governamental. Logo, a discussão sobre a estruturação de qualquer sistema federativo consubstancia a metodologia e a natureza das transferências de recursos de maneira a garantir a eficiência e a equidade na prestação do serviço público (DUARTE et al, 2009) que inevitavelmente atravessa debates tributários e fiscais para financiar as políticas públicas locais (ARRETCHE, 2010), em especial as ações de segurança pública e defesa social.

Os estudos de Mendes, Miranda e Cosio (2008) apresentam algumas características das transferências que contribuem para a manutenção do desenvolvimento sistemático de uma federação democrática. Os autores apresentaram que as transferências, de acordo com o propósito a que se destinam, podem garantir a accountability entre órgãos públicos e sociedade, a redistribuição dos recursos e eficácia das políticas regionais, além da redução do hiato fiscal entre a concentração da arrecadação federal e os gastos estaduais.

Autores como Gomes, Do Carmo e Scarpin (2012) classificaram as transferências mediante critérios orçamentários, podendo ser legais (imperativa por força de lei) ou voluntárias (de acordo com a discricionariedade do transferidor do recurso) que resultam de negociações entre o gestor federal, a 
Revista Científica do Corpo de Bombeiros Militar de Pernambuco

Artigo Publicado no Vol.06 N.17 - Edição Jul a Dez 2020 - ISSN 2359-4829

Versão on-line disponível em: http://www.revistaflammae.com

administração dos órgãos subnacionais e os parlamentares federais. Prado, Quadros e Cavalcanti (2003) classificaram as transferências intergovernamentais conforme a função desempenhada na manutenção do pacto federativo, podendo ser transferência devolutiva tributária, transferência compensatória, transferência redistributiva e transferência discricionária. Já Mendes, Miranda e Cosio (2008), seguindo influência internacional, classificaram as transferências conforme a condicionalidade e contrapartida financeira dos beneficiários.

\section{TRANSFERÊNCIAS VOLUNTÁRIAS}

As transferências intergovernamentais, especialmente as de recursos consignados no Orçamento Geral da União com possibilidade de investimento em áreas temáticas, são instrumentos de maneabilidade racional para estabilizar o federalismo fiscal (GOMES; DO CARMO; SCARPIN, 2012). Os repasses de recursos são principalmente de natureza obrigatória (estruturais), contudo, por vezes, são insuficientes para atendimento dos propósitos dos entes nacionais, assim sendo auxiliados pelas transferências especialmente voluntárias (PRADO; QUADROS; CAVALCANTI, 2003).

A estrutura normativa e os processos para execução das TVGF são necessários para o equilíbrio fiscal federativo, mesmo estando com ineficiências e apresentando diversos gargalos de processo (D'ABADIA, 2015). Considerando que o art. 23 da Constituição Federal (BRASIL, 1988) estabeleceu várias competências comuns ou concorrentes para as entidades federadas e que, para a efetividade pública, deve haver uma repartição adequada das receitas arrecadadas, as TVGF apresentam-se como uma modalidade de transferências de recursos que possibilita a integração dos governos na consecução dos objetivos de segurança pública. 


\section{Revista FLAMMAE}

Revista Científica do Corpo de Bombeiros Militar de Pernambuco

Artigo Publicado no Vol.06 N.17 - Edição Jul a Dez 2020 - ISSN 2359-4829

Versão on-line disponível em: http://www.revistaflammae.com

O governo federal, através do pacto federativo e observando o princípio da desconcentração ${ }^{3}$, distribui competências de sua responsabilidade aos órgãos públicos com parcelas de decisão e atribuição que Ihes cabem (TAVEIRA, 2011). As administrações públicas regionais, com maior competência no diagnóstico microeconômico, provocam da esfera supranacional reforço orçamentário a fim de financiar as ações públicas locais, em apoio mútuo no alcance dos objetivos governamentais.

Destaca-se que no âmbito da execução do orçamento federal, há na Constituição Federal de 1988, na Lei de licitações e contratos da Administração Pública ${ }^{4}$ (BRASIL, 1993), e no escopo da Lei de Responsabilidade Fiscal (BRASIL, 2000) previsão de repasse de recursos através de transferências voluntárias:

Art. 25. Para efeito desta Lei Complementar, entende-se por transferência voluntária a entrega de recursos correntes ou de capital a outro ente da Federação, a título de cooperação, auxílio ou assistência financeira, que não decorra de determinação constitucional, legal ou os destinados ao Sistema Único de Saúde. (LC n 101, 04maio00).

As TVGF são executadas discricionariamente de acordo com os interesses da gestão pública federal (MOUTINHO, 2016; GOULART, 2015), cabendo à administração federal sua análise e aprovação, porém condicionadas ao planejamento orçamentário (LIMONGI; FIGUEIREDO, 2005). Autores como Bijos (2013) apontaram as transferências voluntárias como meio para viabilizar suporte de investimento ao desenvolvimento dos projetos estaduais, podendo ser viabilizados por alianças estratégicas entre lideranças políticas, gestores federais e parlamentares que articulam destinação de recursos.

A captação de recursos federais por meio de consignação orçamentária de algum congressista (senador ou deputado federal), através de Emenda ao Projeto de Lei Orçamentária Anual (PLOA), é modalidade bastante disputada

\footnotetext{
${ }^{3}$ Considera-se desconcentração quando a administração pública distribui, delega suas competências a outros órgãos como medida de alcance dos objetivos do governo.

${ }^{4}$ Lei $\mathrm{n}^{\circ}$ 8.666, de 21 de junho de 1993 - Regulamenta o art. 37, inciso XXI, da Constituição Federal, institui normas para licitações e contratos da Administração Pública e dá outras providências.
} 
Revista Científica do Corpo de Bombeiros Militar de Pernambuco

Artigo Publicado no Vol.06 N.17 - Edição Jul a Dez 2020 - ISSN 2359-4829

Versão on-line disponível em: http://www.revistaflammae.com

no cenário político brasileiro. Obedecendo às diretrizes orçamentárias e legais (RIBEIRO, 2010), o Poder Executivo da União têm o compromisso de avaliar a viabilidade técnica e possui o poder discricionário em decisão fundamentada de financiar ou não o projeto dos órgãos subnacionais.

A execução do orçamento das ações temáticas advindo das Emendas Individuais Parlamentares ${ }^{5}$ são vinculadas a projetos técnicos no Sistema de Convênios Federais - SICONV (BRASIL, 2016), atualmente denominado Plataforma +Brasil. Menciona-se então que a captação de recursos federais se fundamenta por meio de acordos de mútua cooperação entre a União e órgãos públicos denominados Convênios. Assim, a Portaria Interministerial no 424/17 regulamenta a matéria atualizando o conceito de convênio federal:

Convênio: acordo ou ajuste que discipline a transferência de recursos financeiros de dotações consignadas nos Orçamentos Fiscais e da Seguridade Social da União e tenha como partícipe de um lado, órgão ou entidade da administração pública federal, direta ou indireta, e, de outro lado, órgão ou entidade da administração pública estadual ou municipal, direta ou indireta, visando a execução de programa de governo, envolvendo a realização de projeto, atividade, serviço, aquisição de bens ou evento de interesse recíproco, em regime de mútua cooperação (BRASIL, 2017).

\section{RELAÇÃO ENTRE INDICE DE DESENVOLVIMENTO E INDICADOR DE CAPTAÇÃO DE TRANSFERÊNCIA VOLUNTÁRIA}

O interesse de analisar o nível de desenvolvimento das localidades fez com que ferramentas de gestão se desenvolvesse para demonstrar numericamente o status da sociedade por meio de fator capacidade financeira, saúde e informação (conhecimento), conforme parâmetros de longevidade (saúde), conhecimento (educação) e padrão de vida (renda) do Índice de Desenvolvimento Humano (IDH) visam mensurar o crescimento social a partir das condições dos indivíduos (PINTO et al, 2013).

\footnotetext{
${ }^{5}$ Emenda Individual é a modalidade que os Deputados Federais e Senadores têm para adicionar orçamento à PLOA, ou seja, emendar proposta orçamentária ao projeto de lei orçamentária. Esta "adição" ao orçamento federal deve ser alocada em algum Ministério que o executará. Logo, a regra geral é que o parlamentar aloque recursos para execução de projeto de seu interesse em determinado Ministério através da ação orçamentária específica deste.
} 
Revista Científica do Corpo de Bombeiros Militar de Pernambuco

Artigo Publicado no Vol.06 N.17 - Edição Jul a Dez 2020 - ISSN 2359-4829

Versão on-line disponível em: http://www.revistaflammae.com

Da importância do IDH global à adaptação às especificidades brasileiras através do IDHM (Pinto et al, 2013), busca-se a significância de demonstrar e comparar no tempo e no espaço o status quo das localidades, as fraquezas e as distâncias para a situação satisfatória de desenvolvimento. $O$ aproveitamento ideológico do IDH Global para o IDH municipal funcionou para avaliar o desenvolvimento social no âmbito do Município, assim a adaptação também é possível para mensurar o desenvolvimento institucional dos órgãos públicos, especificamente quanto na potencialidade de manter a sustentabilidade organizacional por meio de captação de recursos por transferências voluntárias. Desta forma, as três dimensões do IDHM brasileiro (longevidade, educação e renda) foram correlacionadas como dimensões de capacidades da gestão governamental: técnica, política e conhecimento.

A dimensão técnica guarda a essência da dimensão longevidade do IDHM, pois, considerando que a saúde e longevidade de uma pessoa jurídica devem passar pelas práticas de gestão (humana, material, procedimental e informacional), aponta-se que os índices de saúde de instituição pública estão relacionados às aperfeiçoadas técnicas de gestão, ao exercício assertivo do planejamento organizacional e processos contínuos de informações. Desta forma, a dimensão técnica (administrativa) se relaciona com as competências de monitoramento do ambiente, economicamente e administrativamente, abordando questões sobre percepção orçamentária dos programas de governo federal, análise do PPA federal, LOA e etc. Nesta dimensão, observa-se a gestão dos órgãos por meio de habilidades de planejamento, métodos de análises internas e externas, procedimentos de diagnósticos, percepção do cenário econômico, além de conhecimento em elaboração e gestão de projetos.

A qualidade de vida dos indivíduos requer saúde física e mental (GUIMARÃES; JANNUZZI, 2005), já o desenvolvimento dos órgãos subnacionais requer práticas eficientes de gestão de procedimentos e informações. A sociedade deseja a "saúde" dos órgãos públicos, em especial 


\section{Revista FLAMMAE}

Revista Científica do Corpo de Bombeiros Militar de Pernambuco

Artigo Publicado no Vol.06 N.17 - Edição Jul a Dez 2020 - ISSN 2359-4829

Versão on-line disponível em: http://www.revistaflammae.com

aqueles que detêm a competência legal de prestar os serviços de emergência e defesa social. Observando as dificuldades na atividade de captar e executar as TVGF, pode-se considerar que, a capacitação técnica dos gestores é variável à longevidade institucional pública, além de esclarecer entraves ao desenvolvimento dos serviços à população (PINTO et al, 2013).

A dimensão Instrução aponta para o nível de informações sobre as possibilidades de captação de recursos, bem como, os procedimentos que a norma exige para se conseguir executar o orçamento da União. Desta maneira, a instrução deve ser exercício frequente para os gestores públicos conhecerem os procedimentos e processos que regem as transferências voluntárias. $O$ conhecimento possibilitará caminhos de investimento público, ensejará que a administração vislumbre busca de recursos da União para ampliar o nível de investimento na modernização dos equipamentos e viaturas do serviço de emergência e segurança pública.

A terceira dimensão do IDHM é a renda (padrão de vida) que, no contexto da gestão dos órgãos públicos, mantém correlação com a atividade política já que se refere à renda como meio de acesso às oportunidades das ações governamentais e instrumento para se conseguir os recursos orçamentários necessários para os investimentos corporativos. Entende-se que, para uma pessoa jurídica de direito público interno, como os órgãos estaduais, obter sucesso no continuado aparelhamento e modernização dos serviços, deve-se considerar a atividade política como fator crítico para o desenvolvimento das gestões, já que estão submetidas aos direcionamentos de um sistema político historicamente clientelista e patrimonialista. Destaca-se que o fator político é imprescindível para o sucesso dos órgãos públicos, especialmente quando se tratar de programa de governo e direcionamentos orçamentários, quiçá, contingenciamento orçamentário.

O fator político se assemelha com a dimensão "renda" do IDHM, já que visa mensurar a acessibilidade das instituições ao orçamento público federal, seja por escolha uníssona do governo federal, seja na destinação orçamentária 
Revista Científica do Corpo de Bombeiros Militar de Pernambuco

Artigo Publicado no Vol.06 N.17 - Edição Jul a Dez 2020 - ISSN 2359-4829

Versão on-line disponível em: http://www.revistaflammae.com

através de emendas parlamentares (individuais, de bancada ou comissão). De certo, o envolvimento político do órgão, ou melhor, a habilidade política da gestão favorece sobremaneira o alcance da captação de recursos, pois possibilita destravar processos burocráticos, facilitar a fluidez e comunicação até a esfera federal, além de atrair interesse dos políticos para investimento na temática de segurança e defesa social, em especial às ações finalísticas de atendimento às emergências em todos os seus escopos.

\section{O CBMPE - GOVERNANÇA ESTADUAL DOS SERVIÇOS DE EMERGÊNCIAS}

O Corpo de Bombeiros Militar de Pernambuco (CBMPE), instituição militar do Estado, organizada institucionalmente por força da Lei Estadual $n^{\circ} 15.187$, de 12 de dezembro de 2013 (Lei de Organização Básica do Corpo de Bombeiros Militar do Estado de Pernambuco - LOB/CBMPE) é "instituição permanente, força auxiliar e reserva do Exército Brasileiro, organizado com base na hierarquia e disciplina, destina-se a realizar serviços específicos de bombeiro militar e atividades de defesa civil na área do Estado de Pernambuco".

O CBMPE é órgão público estadual da Administração direta integrante da Secretaria de Defesa Social (art. $3^{\circ}$ da LOB/CBMPE), e consequentemente de natureza na área de segurança pública. Considerando que a temática governamental do CBMPE abrange a proteção social, a missão institucional está pautada nas atividades sócio-políticas de "Promover a preservação da vida, do patrimônio e do meio ambiente, através das ações de prevenção e extinção de incêndios, resgate, busca e salvamento e atendimento préhospitalar no Estado de Pernambuco, visando o bem-estar social".

O CBMPE integra programa de governo em que realiza ações protetivas por meio de resposta a emergências, fazendo parte da governança de emergência estadual como órgão operativo de segurança. Assim, baseando-se nas premissas de transparência administrativa, responsabilidade e controle 
Revista Científica do Corpo de Bombeiros Militar de Pernambuco

Artigo Publicado no Vol.06 N.17 - Edição Jul a Dez 2020 - ISSN 2359-4829

Versão on-line disponível em: http://www.revistaflammae.com

social, eficiência, foco em resultados e integração institucional com outros órgãos públicos.

A Constituição Federal de 1988, em seu artigo 144 preceitua os Corpos de Bombeiros Militares como órgãos da segurança pública mantenedores da ordem pública e da incolumidade das pessoas. Desta maneira, o Corpo de Bombeiros se consubstancia agente de defesa social e garantidor das respostas governamentais nas atividades de emergência e resposta a desastres. Assim sendo, o CBMPE integra a Defesa Social estadual e possui competências legais de resgate, salvamento, combate a incêndio dentre outras, conforme $o$ art. 2 da LOB/CBMPE.

\footnotetext{
"Art. $2^{\circ}$ Compete ao CBMPE em conformidade da legislação vigente:

I - realizar serviços de prevenção e de extinção de incêndio;

II - realizar serviços de prevenção e de extinção de incêndios em florestas e matas, visando à proteção do meio ambiente, na esfera de sua competência;

III - realizar serviços de resgate, busca e salvamento;

(...)

$\mathrm{V}$ - prestar socorro e atendimento emergencial pré-hospitalar, nos casos de acidentes com vítimas ou a pessoas em iminente perigo; VI - atuar na execução das atividades de defesa civil, dentro de sua área de competência no Sistema Estadual de Defesa Civil(...)" (Lei Estadual $\mathrm{n}^{\circ} 15.187$, de 13DEZ2013).
}

Ademais, o alinhamento dos propósitos do CBMPE, da Secretaria de Defesa Social e as diretrizes públicas de segurança da União se tornam evidentes quando se desenvolvem ações e programas com objetivo de apoiar os órgãos estaduais de emergência com base nas políticas nacionais. Desta forma, a Lei nº 13.675/2018 que institui o Sistema Único de Segurança Pública - SUSP estabelece, dentre outras diretrizes, os seguintes tópicos:

Art. 4. ${ }^{\circ}$ São princípios da Política Nacional de Segurança Pública e Defesa Social:

(...)

VI - eficiência na prevenção e na redução de riscos em situações de emergência e desastres que afetam a vida, o patrimônio e o meio ambiente;

$(\ldots)$

X - proteção da vida, do patrimônio e do meio ambiente;

$(\ldots)$ 
XIII - otimização dos recursos materiais, humanos e financeiros das instituições;

(...)

Art. 5. ${ }^{\circ}$ São diretrizes da Política Nacional de Segurança Pública e Defesa Social:

I - atendimento imediato ao cidadão;

(...)

VII - fortalecimento das instituições de segurança pública por meio de investimentos e do desenvolvimento de projetos estruturantes e de inovação tecnológica;

(...)

Art. 6. ${ }^{\circ}$ São objetivos da PNSPDS:

(...)

II - apoiar as ações de manutenção da ordem pública e da incolumidade das pessoas, do patrimônio, do meio ambiente e de bens e direitos;

III - incentivar medidas para a modernização de equipamentos, da investigação e da perícia e para a padronização de tecnologia dos órgãos e das instituições de segurança pública;

Menciona-se que no Estado de Pernambuco, o Corpo de Bombeiros é órgão subordinado à Secretaria de Defesa Social, assim sendo, o CBMPE não possui autonomia na gestão orçamentária e financeira. Contudo, há a possibilidade dos recursos oriundos da captação de Emendas Parlamentares Federais ou Estaduais serem rubricados e direcionados para aparelhamento e modernização corporativos, já que no âmbito da Lei Orçamentária Anual há Ação Orçamentária específica para investimentos no CBMPE. Desta maneira, a atividade de captação de recursos federais, especialmente as por meio de Emendas Federais, objetiva a consignação de orçamento nas ações estaduais para modernização dos órgãos de segurança ou específicas para a modernização e o aparelhamento dos órgãos de emergência e resposta a desastres como o Corpo de Bombeiros Militar.

\section{INDICADOR DE DESEMPENHO EM GESTÃO PÚBLICA}

O modelo gerencial foi desenvolvido com objetivo de contribuir para o aprimoramento dos processos e ferramentas administrativas que promoveriam maiores controles e organização do serviço público para o enfrentamento da 


\section{Revista FLAMMAE}

Revista Científica do Corpo de Bombeiros Militar de Pernambuco

Artigo Publicado no Vol.06 N.17 - Edição Jul a Dez 2020 - ISSN 2359-4829

Versão on-line disponível em: http://www.revistaflammae.com

crise fiscal dos anos 70 e 80 no Brasil. Então, atrelados à era da informação e ao processo da globalização, os modelos administrativos públicos seguiram a tendência e práticas da esfera da gestão privada das grandes corporações e com elas a base teórica dos métodos eficientes de gestão (PEREIRA; REZENDE, 2017).

Conforme Brandão e Guimarães (2001) a eficiência em gestão, especialmente a pública, pode ser avaliada através de instrumentos de monitoramento das atividades organizacionais já que as competências humanas fazem parte de um amplo contexto da avaliação de desempenho institucional. Os autores argumentam que ferramentas que indiquem o nível de desempenho institucional necessariamente abrangem as dimensões da competência administrativa de pessoas ou equipes: conhecimentos, habilidades e atitudes (DURAND, 1998). A avaliação de desempenho na gestão pública consiste em levantamento de dados institucionais mediante um padrão de análise, seja comportamental, contábil, financeiro, político, social e de opinião pública, com objetivo de situar a instituição e direcioná-la às melhores práticas de gestão (GONZAGA et al; 2017)

Santos e Cardoso (2001) destacam que o monitoramento do desempenho e de competências é tendência na avaliação da gestão governamental. Os órgãos públicos devem buscar o aperfeiçoamento no uso dos recursos na prestação de serviço, assim através de indicadores de desempenho os gestores podem correlacionar a eficiência do gasto público com a efetividade das soluções sociais oferecidas pelos órgãos. Jannuzi (2002) menciona que a utilização de indicadores possibilita aos administradores o acompanhamento contínuo do status quo da capacidade de atendimento da gestão pública aos programas apontando às instituições as prioridades de intervenção.

Pesquisadores como Tirone et al (1992) propuseram que os indicadores de gestão ou sistema de indicadores são elementos de mensuração e monitoramento do progresso alcançado e dos resultados a serem atingidos pela organização. Os indicadores de desempenho são ferramentas que 


\section{Revista FLAMMAE}

Revista Científica do Corpo de Bombeiros Militar de Pernambuco

Artigo Publicado no Vol.06 N.17 - Edição Jul a Dez 2020 - ISSN 2359-4829

Versão on-line disponível em: http://www.revistaflammae.com

apontam as causas do problema a fim de aprimorar o desempenho da instituição, sendo utilizados pelos gestores para o controle e melhoria contínua das atividades. Hammond et al. (1995) defendem que os indicadores são variáveis definidas para medir um conceito abstrato relacionado a algum significado socioeconômico com intenção de suprir a gestão de informações estratégicas sobre algum fenômeno. Em outro ponto de observação, os indicadores tem a finalidade de analisar e mensurar variáveis da realidade social subsidiando a tomada de decisão dos gestores públicos. Neste sentido o indicador caracteriza-se de medida quantitativa ou qualitativa organizada e fundamentada com significância que permite descrever, classificar, ordenar, comparar e quantificar a evolução do status quo de um fenômeno. (BRASIL, 2012)

Os indicadores de desempenho na gestão pública, dentre outras funções, servem para medir e gerir o desempenho, analisar o processo de decisão, favorecer a melhoria contínua, subsidiar o planejamento estratégico (SANTOS; CARDOSO, 2001) e o controle do desempenho institucional (CALLADO; CALLADO; ALMEIDA, 2009), além de viabilizar a análise comparativa da instituição com o desempenho de outras instituições. O amadurecimento dos modelos busca conciliar a teoria social com as evidências empíricas observadas, assim é um recurso empiricamente referido para subsidiar atividades teóricas (acadêmica) e programáticas (governo). Observa-se que através do uso de indicadores é possível o aprofundamento da investigação cientifica além da atividade de planejamento público.

\section{DIFERENCIAÇÃO E CLASSIFICAÇÃO}

Os indicadores podem ser diferenciados conforme o objeto e o objetivo da pesquisa institucional. Nesse contexto, Jannuzi (2002), de acordo com a natureza do objeto, classificou os indicadores em indicador-insumo, indicadorproduto ou indicador-processo. Dessa maneira, se o objetivo for acompanhar a alocação e uso de recursos necessários (financeiros, humanos e materiais) à 
Revista Científica do Corpo de Bombeiros Militar de Pernambuco

Artigo Publicado no Vol.06 N.17 - Edição Jul a Dez 2020 - ISSN 2359-4829

Versão on-line disponível em: http://www.revistaflammae.com

execução de alguma atividade classifica-se como indicador-insumo (input indicators). Já o indicador-produto (outcome ou output indicators) é usado com o interesse de avaliar a entrega de produtos à sociedade por parte de alguma instituição ou mesmo conferir empiricamente os resultados da política pública. Os indicadores-processo ou fluxo (throughput indicators) monitoram o esforço da gestão em transformar os insumos em produtos, refere-se às atividades meio do governo.

O estudo de Jannuzi (2002) aponta ainda a classificação de indicadores conforme a avaliação dos efeitos dos esforços da gestão pública. Assim, a classificação os categoriza em "indicador de eficiência" buscando aferir se o objetivo da gestão foi realizado utilizando os recursos disponíveis, "indicador de eficácia" se a política pública foi realizada com aproveitamento e boa gestão dos recursos e "indicador de efetividade" usado para aferir se os esforços da gestão governamental alcançaram efeitos relevantes nos programas sociais.

O Modelo para Mensuração do Desempenho utilizando a Cadeia de Valor e as seis dimensões do Desempenho (6Es) de autoria do Governo Federal do Brasil no ano de 2012, através do Programa para Desburocratização e Excelência em Gestão Pública (GESPÚBLICA), classificou os indicadores de desempenho em seis categorias básicas. Destaca-se que, o referido Programa de Governo, ao analisar modelos de gestão pública utilizados em 12 localidades nacionais e internacionais, observou que as experiências internacionais das metodologias indicam que não há um padrão perfeito de mensuração do desempenho, porém, há modelos que melhor de adaptam às necessidades do gestor e do sistema sócio-governamental.

A definição da metodologia de análise de dados e a construção do modelo de indicador de desempenho devem considerar as características da gestão, assim, condiciona-se a elaboração de qualquer modelo à análise do fenômeno a ser aferido. As etapas para modelagem do constructo de avaliação de desempenho contemplam a identificação do nível, dimensão, subdimensão, objetos de mensuração, definição dos indicadores de desempenho (BRANDÃO 
et al, 2008), construção de fórmulas, definição das metas (JANUZZI, 2002), definição do sistema de coleta de dados, validação dos indicadores (RODRIGUES et al, 2003), mensuração dos resultados e análise (interpretação) dos indicadores (BRASIL, 2009a).

\section{O INDICADOR DE GESTÃO DE DESEMPENHO NA CAPTAÇÃO DE TRANSFERÊNCIAS VOLUNTÁRIAS.}

A elaboração de um sistema de indicadores de desempenho é fundamentada na definição das características e das atividades de relevante significado para o desenvolvimento organizacional. Então, considerando as especificidades da administração dos órgãos estaduais no tocante à gestão das transferências intergovernamentais de receita, agrupam-se condições que justificam a adoção da metodologia do Indicador de Desempenho na Captação de Transferências Voluntárias (IDCTV) no âmbito do Corpo de Bombeiros Militar de Pernambuco.

As condições de realização das transferências voluntárias à esfera estadual consubstancia atividade governamental composta por diversos elementos. A gestão de transferência de recursos envolve esforço administrativo e político, de certo, é atividade com diversas dificuldades ao sucesso. Então, argumenta-se, com base no modelo federativo brasileiro de políticas públicas e nos requisitos técnicos paras as TVGF, o método do IDCTV foi adotado nesta pesquisa como meio para mensurar os elementos do processo de transferência voluntária aos órgãos estaduais de segurança e emergência.

O Indicador de Desempenho na Captação de Transferências Voluntárias é um sistema constituído de vários indicadores. O sistema é composto por 13 indicadores que são organizados em três dimensões, as quais são subdivididas em fatores, conforme apresentado no Anexo 1. 


\section{AS DIMENSÕES DO INDICADOR DE DESEMPENHO NA CAPTAÇÃO DE TRANSFERÊNCIAS VOLUNTÁRIAS NO ÂMBITO DO CORPO DE BOMBEIROS MILITAR DE PERNAMBUCO.}

\subsection{Dimensão Política}

A Dimensão Política agrupa dois fatores - o fator "Quem indica e empurra" e o fator "Quem segura". Destaca-se que as nomenclaturas de tais fatores tentam exprimir a natureza da atividade política que possui influência na captação, negociação e liberação de recursos federais através de projetos públicos de transferências voluntárias. O sistema federativo brasileiro, conforme defendemos nos capítulos anteriores possui raízes muito fortes no patrimonialismo e clientelismo políticos. O poder dos relacionamentos define a arena política em defesa das destinações de recursos aos estados e nas diversas áreas temáticas.

A força das alianças políticas é definida conforme a quantidade de apoio no nível estratégico do governo como quem possui a melhor relação com o centro do poder político federal, independente se o centro do poder for um grupo de pessoas ou uma pessoa. A destinação de recursos orçamentários passa pelo crivo da análise subjetiva em administrar conforme os critérios pessoais em detrimento dos critérios técnicos. Assim, as diretrizes de investimento público e aceitação da viabilidade do projeto pode ser resultado da relação entre o solicitante (órgão público proponente) e o solicitado (gestor estratégico do governo federal) ou entre o gestor do órgão público e os congressistas. Objetivando o retorno político dos recursos, é que os congressistas indicam projetos públicos para beneficiar seus eleitores, sua região e consequentemente sua imagem política. $\mathrm{O}$ fator "Quem indica e empurra" agrupa variáveis que buscam mensurar o quanto de relacionamento político-estratégico a instituição mantém. 
Revista Científica do Corpo de Bombeiros Militar de Pernambuco

Artigo Publicado no Vol.06 N.17 - Edição Jul a Dez 2020 - ISSN 2359-4829

Versão on-line disponível em: http://www.revistaflammae.com

As Organizações Estaduais que possuem apoio parlamentar para "indicar" recursos por Emendas Parlamentares e "empurrar" projetos no Congresso e nos Ministérios possuem maiores probabilidades de receber recursos e consequentemente maior desempenho na captação. Esse fator é constituído por dois indicadores: Quantidade de orçamento Recebido (QOR), Emendas Individuais Recebidas (EIR). O QOR é o coeficiente entre a quantidade de orçamento, por emendas individuais, destinado ao órgão ao longo do atual mandato de deputados federais e o orçamento destinado aos outros entes subnacionais no território estadual. O EIR é o coeficiente entre a quantidade de emendas individuais que o município recebeu no atual mandato de deputado federal e o total de emendas individuais a outros órgãos estaduais no atual mandato de deputado federal.

O fator "Quem segura" é composto por dois indicadores: "Parlamentares Direcionadores de Emendas (PDE)" e o "Ministérios com Relacionamento com Gestores (MRG)". O PDE é o coeficiente entre a quantidade de parlamentares que direcionaram emendas individuais ao município e o total de parlamentares federais do Estado. O MRG é o coeficiente entre a quantidade de Ministérios que o município mantém relacionamento com os analistas de projetos versus o total de Ministérios.

\subsection{Técnico-administrativa}

A dimensão técnica é consubstanciada por dois fatores: Planejamento Organizacional e Gestão de Projetos. Essa dimensão tem o objetivo de mensurar o nível de capacidade técnica que a gestão municipal possui para processar suas atividades e executar as transferências voluntárias. As competências técnicas da equipe gestora possibilitam a efetiva captação e execução dos recursos discricionários.

O planejamento organizacional é instrumento para alinhar as prioridades corporativas com as oportunidades oferecidas pelas políticas de segurança 


\section{Revista FLAMMAE}

Revista Científica do Corpo de Bombeiros Militar de Pernambuco

Artigo Publicado no Vol.06 N.17 - Edição Jul a Dez 2020 - ISSN 2359-4829

Versão on-line disponível em: http://www.revistaflammae.com

pública e emergência, especialmente apontando aos gestores a consonância dos interesses do Corpo de Bombeiros com as diretrizes do Plano Plurianual e dos Programas de governo da União. Além de que o fator Gestão de Projetos é requisito de empoderamento da administração estadual em detectar possibilidades e elaborar projeto alinhado com os resultados esperados das políticas de segurança pública, atendimento à emergências e resposta a desastres. O fator técnico-administrativo é relevante devido aos requisitos técnico-normativos impostos para execução das transferências voluntárias nas Portarias Interministeriais e Plataforma +Brasil.

O fator Planejamento Organizacional busca mensurar o esforço institucional para se preparar ao contexto sociopolítico. A gestão pública que reúne atenção e energia para diagnosticar o ambiente, torna-se mais efetiva no negócio público. O processo de planejar possibilita o constante direcionamento à efetividade das políticas públicas locais, além de preparar a Corporação para infortúnios em tempos de crise. Assim, instrumentos de planejamento aumentam as possibilidades da Organização Militar Estadual na captação de recursos, já que sistemas organizados de diagnóstico de desenvolvimento local apontam as necessidades de aparelhamento e modernização, ao passo que, monitoram o orçamento e a execução das ações governamentais. Assim, o planejamento deve alinhar as propostas de TVGF com as carências institucionais, porém, em consonância com as prioridades do governo federal.

O fator Planejamento Organizacional é composto por quatro indicadores:

a) Instrumento de Planejamento Estratégico (IPE) - Considera-se que a gestão estratégica é uma prática que posiciona a administração no constante atendimento às perspectivas da sociedade, orçamento, fornecedores e comunidade política através da identificação das oportunidades de parcerias, acordos e convênios (incremento ao orçamento). Os órgãos que elaboram os projetos ao longo do tempo possuem maiores chances de executar transferências voluntárias. Desta forma, esse indicador monitora se é utilizado algum instrumento de planejamento estratégico ou de avaliação da gestão. 
Revista Científica do Corpo de Bombeiros Militar de Pernambuco

Artigo Publicado no Vol.06 N.17 - Edição Jul a Dez 2020 - ISSN 2359-4829

Versão on-line disponível em: http://www.revistaflammae.com

b) Monitoramento de políticas públicas (MPP) - Aponta se a gestão possui metodologia para monitoramento das políticas públicas federais, além da análise do Plano Plurianual, Programas, Ações, Estratégias, Iniciativas, Objetivos e Metas do Governo Federal. Os projetos para captação de recursos federais devem coadunar as necessidades de investimento local com as prioridades do Governo Central. Quanto mais a administração proponente souber sobre as políticas federais maiores as oportunidades de antecipação assertiva do projeto e consequente aprovação para executar a transferência voluntária.

c) Monitoramento do orçamento e de políticos (MOP) - Este indicador apresenta o nível de esforço em monitorar a disponibilidade de orçamento federal, considerando a execução e o contingenciamento do orçamento. O acompanhamento é relevante para manter informação sobre a Lei de Diretrizes Orçamentárias (LDO) e Lei Orçamentária Anual (LOA) da União, além do status quo das ações orçamentárias que possibilitam investimento na Corporação Militar Estadual. Assim, a existência de rotina organizada para o monitoramento do orçamento público também deve ser considerada, bem como o monitoramento proativo em busca de oportunidades, considerando o acompanhamento das prioridades dos parlamentares. A entidade pública que conhece a região, programas temáticos, estratégias, coligações políticas de cada parlamentar possui, em tese, uma maior visão para acertar na proposta de projeto de interesse do congressista. Desta maneira, a gestão que possui alguma metodologia para diagnosticar e produzir informações estratégicas sobre orçamento federal e pretensões parlamentares, apresenta-se com melhores possibilidades para conseguir Emendas Parlamentares e destinações de transferências voluntárias.

d) Assessoria Parlamentar de Articulação (APA) - O exercício da atividade politico-administrativa dos órgãos públicos deve considerar a vital articulação com os agentes sociais. Considerando que o sistema de transferências intergovernamentais possui gargalos submetidos à discricionariedade do poder 
central, a participação ativa de representantes dos organismos subnacionais junto ao centro de poder federal é fundamental na facilitação de liberações, destraves processuais, prioridades no descontingenciamento do orçamento, foco nas políticas públicas de segurança e defesa social, além das fontes e destinações de recursos. Assim, quanto mais a Organização Militar Estadual seja ativa nos relacionamentos com os poderes Executivo e Legislativo federais, maiores chances de captação de recursos. Então, o Corpo de Bombeiros Militar que mantém assessores parlamentares ou representantes institucionais na capital do país, consegue mais facilitações aos projetos de desenvolvimento. Esse indicador, também, pontua se o representante institucional é conhecedor do processo legislativo federal, já que o orçamento é sugerido pelo Poder Executivo, porém bastante influenciado pelo Legislativo, principalmente por meio das Emendas Parlamentares.

O Fator Gestão de Projetos é parte da dimensão técnica, em decorrência de exprimir requisitos à competência administrativa, na qualidade de planejamento das atividades e na eficácia dos resultados. O grupo administrativo, quando possui expertise na condução de projetos, pode possibilitar bom fluxo de atividades e produtos de qualidade.

A elaboração de projetos de convênios requer que o administrador conheça os requisitos normativos, os processos governamentais e os meandros políticos. Dessa maneira, a celebração de convênios perpassa por projetos que atendam as demandas sociais e governamentais sem perder 0 foco na gestão do tempo, do orçamento e das atividades.

O desempenho na produção e na execução de projetos públicos, especialmente de convênios e contratos de repasse, pode estar diretamente relacionado com a quantidade de servidores formados ou capacitados na elaboração e análise de projetos de convênios.

O Fator de gestão de projetos possui dois indicadores:

a) Servidores com Capacitação em Projetos (SCP) - Este indicador objetiva apresentar o status técnico em projetos a partir do potencial Know-how 
Revista Científica do Corpo de Bombeiros Militar de Pernambuco

Artigo Publicado no Vol.06 N.17 - Edição Jul a Dez 2020 - ISSN 2359-4829

Versão on-line disponível em: http://www.revistaflammae.com

dos servidores envolvidos com convênios. A competência na elaboração de projetos potencializa a consubstanciação das intenções em plano organizado, coerente e racional. A ausência de projetos sólidos e robustos causa incredibilidade da intenção, além de não demonstrar adequação aos princípios da eficiência administrativa, economicidade processual, publicidade e impessoalidade através da técnica. A competência de elaboração de projetos, em conformidade com os Decretos, Leis e normativos, é requisito para aceitação e execução das transferências voluntárias. Logo, a elaboração de bons projetos de convênios é condição para que o convênio não seja classificado em "Impedimento Técnico".

b) Autoria dos projetos de Transferência Voluntária (APTV) - A elaboração e a execução do projeto público requerem pessoas com competência técnica específica no âmbito das transferências voluntárias, então, quanto mais a administração envolve pessoas com conhecimento específico em convênios federais, melhor o desempenho técnico. Ademais, todo o processo de celebração e execução dos convênios acontece pela Plataforma +Brasil, que exige conhecimentos normativos e técnicoadministrativos. Então, acredita-se que quanto mais conhecimento potencial o órgão possuir, melhor desempenho obterá. Este indicador considera, até mesmo, a contratação de empresa especializada em prestar assessoria no âmbito de transferência voluntária.

\subsection{Dimensão Conhecimento}

A gestão da informação no âmbito dos órgãos torna-se fator crítico para a administração obter sucesso na captação de recursos discricionários, já que o assunto, embora relevante, é de domínio de poucos servidores. Assim, a gestão que se preocupa em manter círculo virtuoso de transferência de informação sobre a matéria, provavelmente possui mais capacidade para 


\section{Revista FLAMMAE}

Revista Científica do Corpo de Bombeiros Militar de Pernambuco

Artigo Publicado no Vol.06 N.17 - Edição Jul a Dez 2020 - ISSN 2359-4829

Versão on-line disponível em: http://www.revistaflammae.com

buscar oportunidades, pratica o empreendedorismo público e minimiza entraves técnico-burocráticos.

O conhecimento sobre a matéria abrange a esfera normativa com informações sobre os normativos federais (legislações, decretos, instruções normativas e portarias interministeriais), a esfera técnica com informações nas áreas de administração pública, elaboração de projetos e sistema de convênios federais, além de conhecimentos na esfera política por meio da expertise sobre processo legislativo e calendário para sanção da Lei Orçamentária Anual.

Essa dimensão é composta por dois fatores: Gestão do Conhecimento e Capacitação.

O fator Gestão do Conhecimento possui um indicador:

a) Capacitações realizadas a servidores (CRS). Esse é um indicador que objetiva mensurar o esforço da gestão em aprimorar seus processos. A gestão da informação administrativa, especialmente na gestão dos convênios federais, é negligenciada e interrompida por ausência de conhecimento técnico. Porém, é possível que os usuários do SICONV, recebam treinamento sobre o manuseio do sistema, em projetos públicos e captação de recursos. O indicador afere a quantidade de cursos sobre projetos e convênios federais promovidos aos servidores nos últimos 24 meses.

O fator Capacitação possui dois indicadores:

a) Servidores capacitados para operar o SICONV-Plataforma +Brasil (SCS) - em paralelo à quantidade de servidores cadastrados, é fundamental conhecer o coeficiente de servidores que de fato foram treinados para operar na Plataforma +Brasil, anteriormente conhecida como SICONV (Sistema de Convênios Federais). Busca-se com essa mensuração a quantidade de servidores cadastrados no Sistema de Convênios Federais que possui competência de processamento. Espera-se que esse indicador demonstre o nível de Know-how da instituição na Plataforma +Brasil. 


\section{Revista FLAMMAE}

Revista Científica do Corpo de Bombeiros Militar de Pernambuco

Artigo Publicado no Vol.06 N.17 - Edição Jul a Dez 2020 - ISSN 2359-4829

Versão on-line disponível em: http://www.revistaflammae.com

b) Servidores que dominam a Portaria Interministerial (SDPI). $O$ conhecimento da Portaria Interministerial pode apontar o nível de informação da entidade subnacional. De maneira inequívoca, deve-se conhecer a Portaria Interministerial $n^{\circ} 424$ /MP/MF/CGU de 30 de dezembro de 2016 (PI 424/16) a qual define os requisitos e as diretrizes para apresentação de propostas de convênios, além da celebração com os órgãos federais, execução e prestação de contas. Esse indicador apresenta uma ponderação para a quantidade de servidores que dominam a PI 424/16.

\section{A ESTRUTURA DO INDICADOR}

O Indicador de Desempenho na Captação de Transferências Voluntárias aplicado à contextualização do Corpo de Bombeiros Militar de Pernambuco foi submetido à necessária revisão e ajuste das variáveis originais do IDCTV apontadas por Costa (2018) e apresentadas no Apêndice 1.

Nessa contextualização do CBMPE e com base na revisão do modelo de Costa (2018) foram adotados os parâmetros metodológicos de pesquisa institucional, bem como os critérios e ponderações dos fatores e indicadores menores, além da métrica do peso das variáveis conforme demonstrado no Apêndice 2.

O IDCTV reúne 20 variáveis independentes com natureza distintas, podendo ser variável boleana, variável de múltipla escolha e variável com número absoluto. $\mathrm{O}$ valor de cada variável é multiplicado pelo peso correspondente, cujos valores foram definidos conforme metodologia apontada por Costa (2018).

O painel de desempenho é apresentado no Apêndice 4 como ferramenta de mensuração dos elementos influenciadores na captação de recursos por transferências voluntárias. Ademais, em concordância com Hanai (2009) que mencionou a revisão e a avaliação periódica de indicadores, defende-se a realização de exames regulares e aprimoramentos nos elementos de 
desempenho, com objetivo de não se negligenciar a atualização dos requisitos das TVGF.

\section{APLICAÇÕES DO IDCTV AO CORPO DE BOMBEIROS MILITAR DE PERNAMBUCO}

A aplicação do modelo ao Corpo de Bombeiros Militar de Pernambuco considerou as informações obtidas mediante entrevista aos Oficiais (gestores) da Diretoria de Planejamento e Gestão da corporação, já que é o organismo institucional responsável pela elaboração de projetos de captação de recursos, além de obter o conhecimento empírico da articulação nos âmbitos do Poder executivo Federal e Poderes Legislativos (Estadual e Federal).

A obtensão das informações para cálculo do IDCTV aconteceu por meio da técnica da entrevista estruturada adotando como roteiro a relação das variáveis apresentadas no Apêndice 3.

O IDCTV aplicado ao Corpo de Bombeiros Militar de Pernambuco apresenta-se com valor numérico 2 (dois), englobando Dimensão Política em 4,44 (quatro vírgula quarenta e quatro), Dimensão Técnica-administrativa em 2,61 (dois vírgula sessenta e um) e Dimensão Conhecimento em 0,93 (zero vírgula noventa e três). 


\section{Revista FLAMMAE}

Revista Científica do Corpo de Bombeiros Militar de Pernambuco

Artigo Publicado no Vol.06 N.17 - Edição Jul a Dez 2020 - ISSN 2359-4829

Versão on-line disponível em: http://www.revistaflammae.com

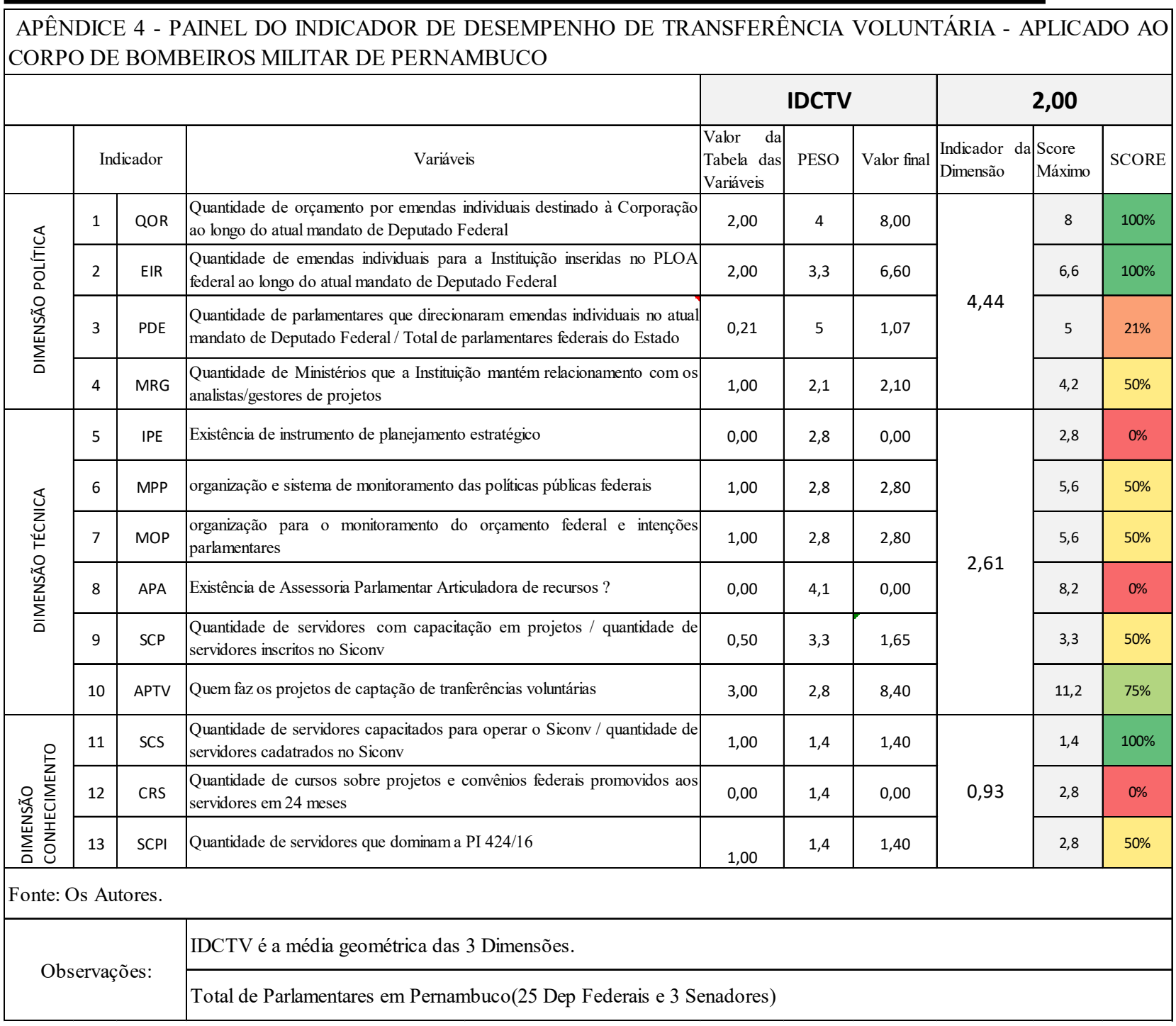

\section{CONCLUSÕES}

Os resultados apresentados nesta pesquisa devem ser o ponto inicial de questionamentos sobre $\mathrm{o}$ balizamento dos recursos públicos para aparelhamento e modernização dos serviços de emergência estaduais que estão permeados pelo debate orçamentário entre poder Executivo e Legislativo. Destaca-se que a exposição da especificidade da temática é relevante aos órgãos subnacionais que planejam captar recursos federais por Emendas Parlamentares Individuais, especialmente órgãos de segurança 
pública, neste estudo, representados pelo Corpo de Bombeiros Militar de Pernambuco.

O estudo sobre direcionamento das Emendas é relevante para $\mathrm{O}$ entendimento do comportamento legislativo dos Deputados Federais e Senadores no Brasil. É através das Emendas que os parlamentares demonstram a práxis do Poder Legislativo no direcionamento das políticas públicas. $O$ inter-relacionamento entre Legislativo e o Executivo é a essência para o entendimento do mecanismo político das destinações das emendas individuais e consequentes investimentos públicos. A atividade de captação de recursos por transferência voluntária deve considerar variáveis políticas, técnicas e informacionais sobre o processo de prospecção e execução de projetos de convênios. Neste contexto o presente estudo testou o modelo do IDCTV e realizou adaptações necessárias ao contexto da administração de órgão de segurança e emergência, apresentando variáveis significantes na atividade de captação de recursos públicos federais por transferências voluntárias.

Destaca-se que a modernização dos órgãos de segurança e emergência objetivando a oferta de melhores serviços à sociedade é resultado dos esforços da gestão local manter negociação constante junto aos parlamentares com interesse de conquistar incrementos no orçamento nas áreas de segurança. As prioridades das políticas públicas são definidas pelo Executivo, porém os congressistas podem selecioná-las por seu interesse. O monitoramento dos fatores de influência por meio do IDCTV demonstra as condições corporativas na captação de recursos e, de alguma maneira, oferecem retorno das fragilidades da corporação, seja pelas deficiências na dimensão política, dimensão técnica-administrativa ou dimensão conhecimento.

Um dos objetivos desse estudo foi apresentar uma possibilidade de viabilizar o fomento às práticas de relacionamento com outras esferas federativas na busca por transferências de recursos que visem o desenvolvimento dos órgãos de emergência. A premissa do autoconhecimento 


\section{Revista FLAMMAE}

Revista Científica do Corpo de Bombeiros Militar de Pernambuco

Artigo Publicado no Vol.06 N.17 - Edição Jul a Dez 2020 - ISSN 2359-4829

Versão on-line disponível em: http://www.revistaflammae.com

corporativo é aperfeiçoar análise do processo e natureza das transferências voluntárias na realização das políticas de segurança no Brasil, já que a gestão dos órgãos públicos, estando pautada na análise política e técnica, pode potencializar as ações governamentais locais.

O IDCTV se mostrou fator de análise e reflexão da realidade institucional, ao revelar algumas fragilidades institucionais na específica atividade de captação de recursos federais. O estudo demonstrou por meio de variáveis aplicadas ao Corpo de Bombeiros Militar de Pernambuco, as condições institucionais a serem aprimoradas nos âmbitos políticos, técnicos e conhecimento, além de apontar as capacidades dos órgãos públicos estaduais de emergência em aprimorar suas captações de recursos por transferências voluntárias.

Ademais, este trabalho deixa legado aos gestores públicos $\mathrm{e}$ pesquisadores da temática para que o modelo seja aplicado a outras Corporações, além de possibilitar o aprimoramento contínuo mediante aperfeiçoamento das variáveis utilizadas bem como os requisitos para celebração de Convênios.

\section{REFERÊNCIAS}

ARRETCHE, Marta. Federalismo e igualdade territorial: uma contradição em termos?. DADOS-Revista de Ciências Sociais, v. 53, n. 3, 2010.

BIJOS, Danilo. Federalismo, instituições políticas e relações intergovernamentais: um estudo sobre os elementos determinantes das transferências voluntárias da União para os municípios do estado de Minas Gerais. 2013. Dissertação (Mestrado em Ciência Política) - Instituto de Ciência Política, Universidade de Brasília, Brasília, 2013.

BRANDÃO, Hugo Pena et al. Gestão de desempenho por competências: integrando a gestão por competências, o balanced scorecard e a avaliação 360 graus. Revista de Administração Pública-RAP, v. 42, n. 5, 2008. 


\section{Revista FLAMMAE}

Revista Científica do Corpo de Bombeiros Militar de Pernambuco

Artigo Publicado no Vol.06 N.17 - Edição Jul a Dez 2020 - ISSN 2359-4829

Versão on-line disponível em: http://www.revistaflammae.com

BRANDÃO, Hugo Pena; GUIMARÃES, Tomás de Aquino. Gestão de

Competências e Gestão de Desempenho: tecnologias distintas ou instrumentos de um mesmo construto? Revista de Administração de Empresas. São Paulo, v. 41, n. 1, p. 8-15. Jan./Mar. 2001.

BRASIL. Ministério do Planejamento, Desenvolvimento e Gestão. Portaria Interministerial $n^{\circ} 507$ de 24 de novembro de 2011. Diário Oficial [da\} República Federativa do Brasil, Poder Executivo, Brasília, DF,. Seção 1, p. 227. 28 nov. 2011.

. Constituição (1988). Constituição da República Federativa do Brasil. Brasília, DF. 1988. Disponível em: www.planalto.gov.br/ccivil_03/constituicao/constituicaocompilado.htm. Acessado em: 20 out $201 \overline{6}$.

Decreto $\mathrm{n}^{\circ} 6.170$, de 25 de julho de 2007. Diário Oficial [da\} República Federativa do Brasil, Poder Executivo Brasília, DF,. Seção 1, p.1. 26 jul. 2007

Lei Complementar $n^{\circ} 101$, de 4 de maio de 2000. Disponível em: http://www.planalto.gov.br/ccivil_03/leis/LCP/Lcp101.htm. Acessado em: 20 out 2016.

. Lei $\mathbf{n}^{\circ}$ 8.666, de 21 de junho de 1993. Diário Oficial [da\} República Federativa do Brasil, Poder Legislativo, Brasília, DF. Seção 1, p.1. , 22 jun. 1993

. Ministério do Planejamento, Desenvolvimento e Gestão. Portaria Interministerial $\mathrm{n}^{\circ} \mathbf{4 2 4}$ de $\mathbf{3 0}$ de dezembro de 2016. Diário Oficial [da\} República Federativa do Brasil, Poder Executivo, Brasília, DF. Seção 1, p. 25. 02 jan. 2017.

. Ministério do Planejamento. Melhoria da Gestão pública por meio da definição de um guia referencial para medição do desempenho da gestão, controle para o gerenciamento dos indicadores de eficiência, eficácia e de resultados do programa nacional de gestão pública e desburocratização.

Produto 1: Mapeamento Bibliográfico e do estado da arte sobre indicadores de gestão. Brasília, DF, 2009a.

. Ministério do Planejamento, Orçamento e Gestão. Indicadores Orientações Básicas Aplicadas à Gestão Pública. Brasília, DF, 2012.

. Ministério do Planejamento. Melhoria da Gestão pública por meio da definição de um guia referencial para medição do desempenho da gestão, controle para o gerenciamento dos indicadores de eficiência, eficácia e de resultados do programa nacional de gestão pública e desburocratização. 


\section{Revista FLAMMAE}

Revista Científica do Corpo de Bombeiros Militar de Pernambuco

Artigo Publicado no Vol.06 N.17 - Edição Jul a Dez 2020 - ISSN 2359-4829

Versão on-line disponível em: http://www.revistaflammae.com

Produto 1: Mapeamento Bibliográfico e do estado da arte sobre indicadores de gestão. Brasília, DF, 2009a.

CALLADO, Aldo Leonardo Cunha; CALLADO, Antônio André Cunha; ALMEIDA, Moisés Araújo. Determinando padrões de utilização de indicadores de desempenho: um estudo em micro e pequenas empresas da cidade de João Pessoa. Contabilidade, Gestão e Governança, v. 11, n. 1-2, 2009.

COSTA, Emmanuel de Oliveira. TRANSFERÊNCIAS VOLUNTÁRIAS DO GOVERNO FEDERAL (TVGF) A MUNICÍPIOS DA REGIÃO METROPOLITANA DO RECIFE: UMA ANÁLISE DO DESEMPENHO DA GESTÃO MUNICIPAL.. 2018. Dissertação (Mestrado em Gestão do Desenvolvimento Local Sustentável) - Faculdade de Faculdade de Ciências da Administração de Pernambuco, Universidade de Pernambuco, Recife, 2018.

D’ABADIA, Bruno Magalhães. A Problemática das Transferências Voluntárias. Estudo(Finanças Públicas). Consultoria Legislativa da Câmara dos Deputados. Brasília, maio, 2015.

DUARTE, Ângelo et al. Transferências fiscais intergovernamentais no Brasil: Uma avaliaçao das transferências federais, com ênfase no sistema único de saúde. Naciones Unidas Comisión Económica para América Latina y el Caribe (CEPAL), Serie Gestión Pública, n. 69, 2009.

DURAND, T. Forms of Incompetence. In: INTERNATIONAL CONFERENCE ON COMPETENCE-BASED MANAGEMENT, 4.,1998, Oslo. Proceedings... Oslo : Norwegian School of Management, 1998.

GOMES, Oliveira; DO CARMO, Ely; SCARPIN, Jorge Eduardo. Estudo Bibliométrico Acerca das Transferências Intergovernamentais Publicadas no Período de 2001 a 2008. Base, v. 9, n. 1, 2012.

GONZAGA, Rosimeire Pimentel; FREZATTI, Fabio; CKAGNAZAROFF, Ivan Beck; SUZART, Janilson Antônio da Silva. Avaliação de Desempenho no Governo Mineiro: Alterações dos Indicadores e Metas. RAC, Rio de Janeiro, v. 21, Edição Especial FCG, art. 1, pp. 1-21, Abril 2017. http://dx.doi.org/10.1590/1982-7849rac2017150331

GOULART, Samuel de Oliveira Reis. Transferências Voluntárias da União: Uma Análise de Eficiência em Municípios Mineiros. Dissertação (mestrado) Universidade FUMEC. Faculdade de Ciências Empresariais. Belo Horizonte, 2015.

GUIMARÃES, J. R. S.; JANNUZZI, P. M. IDH, indicadores sintéticos e suas aplicações em políticas públicas: uma análise crítica. Revista Brasileira de Estudos Urbanos e Regionais, v. 7, n. 1. 2005. 


\section{Revista FLAMMAE}

Revista Científica do Corpo de Bombeiros Militar de Pernambuco

Artigo Publicado no Vol.06 N.17 - Edição Jul a Dez 2020 - ISSN 2359-4829

Versão on-line disponível em: http://www.revistaflammae.com

GUIMARÃES, Roberto P.; FEICHAS, Susana A. Q. Desafios na construção de indicadores de sustentabilidade. Ambiente \& Sociedade, Campinas, v.XII, $\mathrm{n}^{\circ}$ 2, p. 307-323, dez. 2009.

HAMMOND, A;ADRIAANSE,A; RODENBURG, E; BRYANT,D; WOODWARD, R. Environmental Indicators: A systematic approach to measuring and reporting on environmental policy performance in the context of sustainable development. Washington, D.C.: World Resources Institute, 1995.

HANAI, Frederico Yuri. Sistema de indicadores de sustentabilidade: uma aplicação ao contexto de desenvolvimento do turismo na região de Bueno Brandão, Estado de Minas Gerais, Brasil. 2009. Tese (Doutorado em Ciências da Engenharia Ambiental) - Escola de Engenharia de São Carlos (EESC) da Universidade de São Paulo (USP), São Carlos, 2009.

JANNUZZI, Paulo de Martino. Considerações sobre o uso, mau uso e abuso dos indicadores sociais na formulação e avaliação de políticas públicas municipais. Revista de Administração Pública. Rio de Janeiro, v. 36, n. 1, p. 51-72, 2002.

LAKATOS, E. M.; MARCONI, M. A. Metodologia do trabalho científico. $8^{a}$ ed. São Paulo: Atlas, 2017.

LIMONGI, Fernando; FIGUEIREDO, Argelina. Processo orçamentário e Comportamento Legislativo: Emendas Individuais, apoio ao Executivo e Programa de Governo. DADOS - Revista de Ciências Sociais, Rio de Janeiro, Vol.48, no4, pp.737 a 776, 2005.

MENDES, Marcos; MIRANDA, Rogério; COSIO, Fernando. Transferências intergovernamentais no Brasil: diagnóstico e proposta de reforma. Texto Para Discussão $n^{\circ} 40$. Consultoria Legislativa do Senado Federal. Brasília: Senado Federal, p. 111, 2008.

MOUTINHO, José da Assunção. Transferências voluntárias da União para municípios brasileiros: mapeamento do cenário nacional. Revista da

Administração Pública. Rio de Janeiro. Vol. 50, p.151-166, jan./fev. 2016.

ORZIL, Alexandre; AMORIM, Almério Cançado; SIMÕES, Glaucia Maria. Convênios públicos: a nova legislação. Brasília: Orzil Consultoria, 2014.

OSTROVSKI, Dalésio; PASSOS, Messias Modesto dos. Indicadores do Desenvolvimento Sustentável. Revista Eletrônica Científica Inovação e Tecnologia. Medianeira, PR. Vol 01, núm 05. 2012.

PEDERIVA, João Henrique; PEDERIVA, Patrícia Lima Martins. Execução de Emendas Parlamentares Individuais ao Orçamento: mudanças em 2014. Anais do I Encontro Nacional de Ensino e Pesquisa do Campo de Políticas. 


\section{Revista FLAMMAE}

Revista Científica do Corpo de Bombeiros Militar de Pernambuco

Artigo Publicado no Vol.06 N.17 - Edição Jul a Dez 2020 - ISSN 2359-4829

Versão on-line disponível em: http://www.revistaflammae.com

At4. Planejamento, finanças públicas e orçamento. Acesso em 15 maio de 2017. Disponível em: http://www.anepcp.org.br/acp/c/Anais.

PEREIRA, José Roberto; REZENDE, João Batista. Gestão pública municipal. 1 ed. Curitiba, CRV, 2017.

PERNAMBUCO. Lei Estadual $n^{\circ}$ 15.187, de 12 de dezembro de 2013. Diário Oficial [do] Estado de Pernambuco, Poder Executivo. Recife, PE. N² 237, p.6. 13 dez. 2013.

PINTO, D. G.; COSTA, M. A.; MARQUES, M. (Coords.). $O$ índice de desenvolvimento humano municipal brasileiro. Série Atlas do

Desenvolvimento Humano no Brasil. Brasília: PNUD; IPEA; FJP, 2013.

PRADO, Sérgio. Transferências Intergovernamentais na federação brasileira: avaliação e alternativas de reformas. Caderno Fórum Fiscal, n. 6, 2006.

PRADO, Sérgio; QUADROS, Waldemir; CAVALCANTI, Carlos Eduardo G. Partilha de recursos na federação brasileira. Fapesp, 2003.

RIBEIRO, Romiro. Orçamento Público Semi-Impositivo para Transferências Voluntárias: Diagnóstico, Perspectivas E Proposta De Mudanças. E-Legis Revista Eletrônica do Programa de Pós-Graduação, Brasília, n.4, p. 149$167,1^{\circ}$ semestre 2010.

RODRIGUES, Luis Henrique; SCHUCH, Cristiano; PANTALEÃO, Luis Henrique. Uma abordagem para construção de sistemas de indicadores alinhando a teoria das restrições e o Balanced Scorecard. Encontro da Associação Nacional dos Programas de Pós-Graduação em Administração, v. 27, p. 2003, 2003.

SAKURAI, Sergio Naruhiko; THEODORO, Maria Isabel Accoroni. Alinhamento político e transferências governamentais: Novas evidências para os municípios brasileiros. In: Encontro Nacional de Economia, 41., 2013, Anais do XLI

Encontro Nacional de Economia [Proceedings of the 41th Brazilian Economics Meeting] n. 076, ANPEC - Associação Nacional dos Centros de Pós-graduação em Economia, 2014.

SANTOS, Luiz Alberto dos, CARDOSO, Regina Luna dos Santos. Avaliação de Desempenho da Ação Governamental no Brasil: Problemas e Perspectivas. XV Concurso de Ensayos del CLAD "Control y Evaluación del Desempeño Gubernamental". Caracas, 2001.

TAMAKI, Edson Mamoru et al. Metodologia de construção de um painel de indicadores para o monitoramento e a avaliação da gestão do SUS. Ciência \& Saúde Coletiva, v. 17, n. 4, p. 839-849, 2012. 
Revista Científica do Corpo de Bombeiros Militar de Pernambuco

Artigo Publicado no Vol.06 N.17 - Edição Jul a Dez 2020 - ISSN 2359-4829

Versão on-line disponível em: http://www.revistaflammae.com

TAVEIRA, Adriana do Val. Descentralização e desconcentração da atividade estatal. Revista Paradigma, n. 18, 2011.

TIRONI, L. F.(Coord.); SATO, A.K.; FILHO, B.P.; KOZAK, J.C.; MATTOS, R.S.; PESSOA, R.S.; PIOLA, S.F. Indicadores da Qualidade e Produtividade Um Relato de Experiências no Setor Público (Texto para Discussão $n^{\circ} 263$ ). Instituto de Pesquisa Econômica Aplicada. Brasília, DF, 1992. 
Revista Científica do Corpo de Bombeiros Militar de Pernambuco

Artigo Publicado no Vol.06 N.17 - Edição Jul a Dez 2020 - ISSN 2359-4829

Versão on-line disponível em: http://www.revistaflammae.com

\begin{tabular}{|c|c|c|c|c|c|c|c|c|c|c|c|c|c|c|c|c|c|c|c|}
\hline \multicolumn{20}{|c|}{ APÊNDICE 2 - PESO DOS INDICADORES } \\
\hline & & & 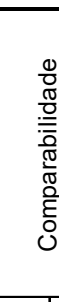 & & 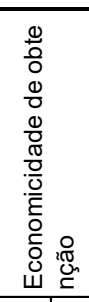 & 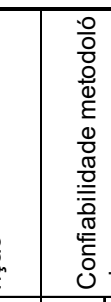 & & 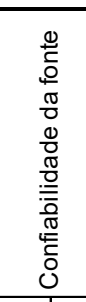 & & $\begin{array}{l}\frac{0}{0} \\
\frac{\pi}{0} \\
: \frac{0}{0} \\
\overline{\overline{0}} \\
\frac{\bar{E}}{0} \\
\end{array}$ & 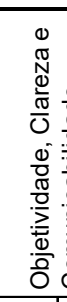 & & 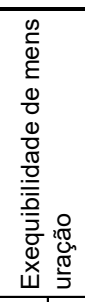 & & 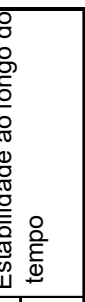 & 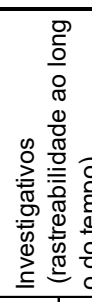 & & 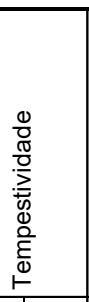 & 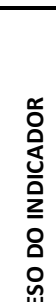 \\
\hline & dimensã & indicador & 1 & peso & \begin{tabular}{l|l}
2 & pe \\
\end{tabular} & \begin{tabular}{l|l|l|} 
eso & 3 \\
\end{tabular} & \begin{tabular}{|l|} 
peso \\
\end{tabular} & \begin{tabular}{l|l|l}
4 & $\mathrm{pe}$ \\
\end{tabular} & \begin{tabular}{l|l} 
eso \\
\end{tabular} & \begin{tabular}{l|l}
5 & pesc \\
\end{tabular} & \begin{tabular}{l|l|l}
6 \\
\end{tabular} & peso & \begin{tabular}{l|l}
7 & $\mathrm{pe}$ \\
\end{tabular} & \begin{tabular}{|l|l|} 
eeso & 8 \\
\end{tabular} & peso & \begin{tabular}{l|l}
9 & $\mathrm{pe}$ \\
\end{tabular} & \begin{tabular}{l|l} 
peso & 10 \\
\end{tabular} & \begin{tabular}{|l|l|} 
& peso \\
\end{tabular} & \\
\hline 1 & \multirow{4}{*}{ 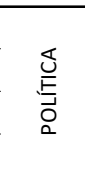 } & QOR & 1 & & 0 & 1 & & 1 & \multirow{13}{*}{7} & 1 & 1 & & 1 & 1 & & 1 & 0 & \multirow{13}{*}{4} & 4 \\
\hline 2 & & EIR & 0 & & 1 & 1 & & 1 & & 0 & 0 & & 1 & & & 1 & & & 3,3 \\
\hline 3 & & PDE & 1 & & 1 & 1 & & 1 & & 1 & 1 & & 1 & & & 1 & 1 & & 5 \\
\hline 4 & & MRG & 0 & & 0 & 0 & & 1 & & 1 & 1 & & 1 & & & 0 & 0 & & 2,1 \\
\hline 5 & \multirow{6}{*}{$\underbrace{\mathbb{S}}_{\breve{H}}$} & IPE & 1 & & 0 & 0 & & 1 & & 1 & 1 & & 1 & & & 0 & 0 & & 2,8 \\
\hline 6 & & MPP & 1 & & 0 & 0 & & 1 & & 1 & 1 & & 1 & 0 & & 0 & 0 & & 2,8 \\
\hline 7 & & MOP & 1 & 7 & 0 & 0 & 5 & 1 & & 4 & 1 & 3 & 1 & 0 & 3 & 0 & 4 & & 2,8 \\
\hline 8 & & APA & 1 & & 0 & 1 & & 1 & & 1 & 1 & & 1 & 0 & & 1 & 1 & & 4,1 \\
\hline 9 & & SCP & 1 & & 0 & 1 & & 1 & & 1 & 1 & & 1 & 0 & & 0 & 0 & & 3,3 \\
\hline 10 & & APTV & 1 & & 0 & 0 & & 1 & & 1 & 1 & & 1 & 0 & & 0 & 0 & & 2,8 \\
\hline 11 & \multirow{3}{*}{ 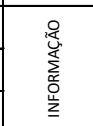 } & SCS & 1 & & 0 & 0 & & 0 & & 1 & 1 & & 0 & 0 & & 0 & 0 & & 1,4 \\
\hline 12 & & CRS & 0 & & 0 & 0 & & 1 & & 1 & 1 & & 0 & 0 & & 0 & 0 & & 1,4 \\
\hline 13 & & SCPI & 1 & & 0 & 0 & & 0 & & 1 & 1 & & 0 & 0 & & 0 & 0 & & 1,4 \\
\hline
\end{tabular}


Revista Científica do Corpo de Bombeiros Militar de Pernambuco

Artigo Publicado no Vol.06 N.17 - Edição Jul a Dez 2020 - ISSN 2359-4829

Versão on-line disponível em: $\underline{\text { http://www.revistaflammae.com }}$

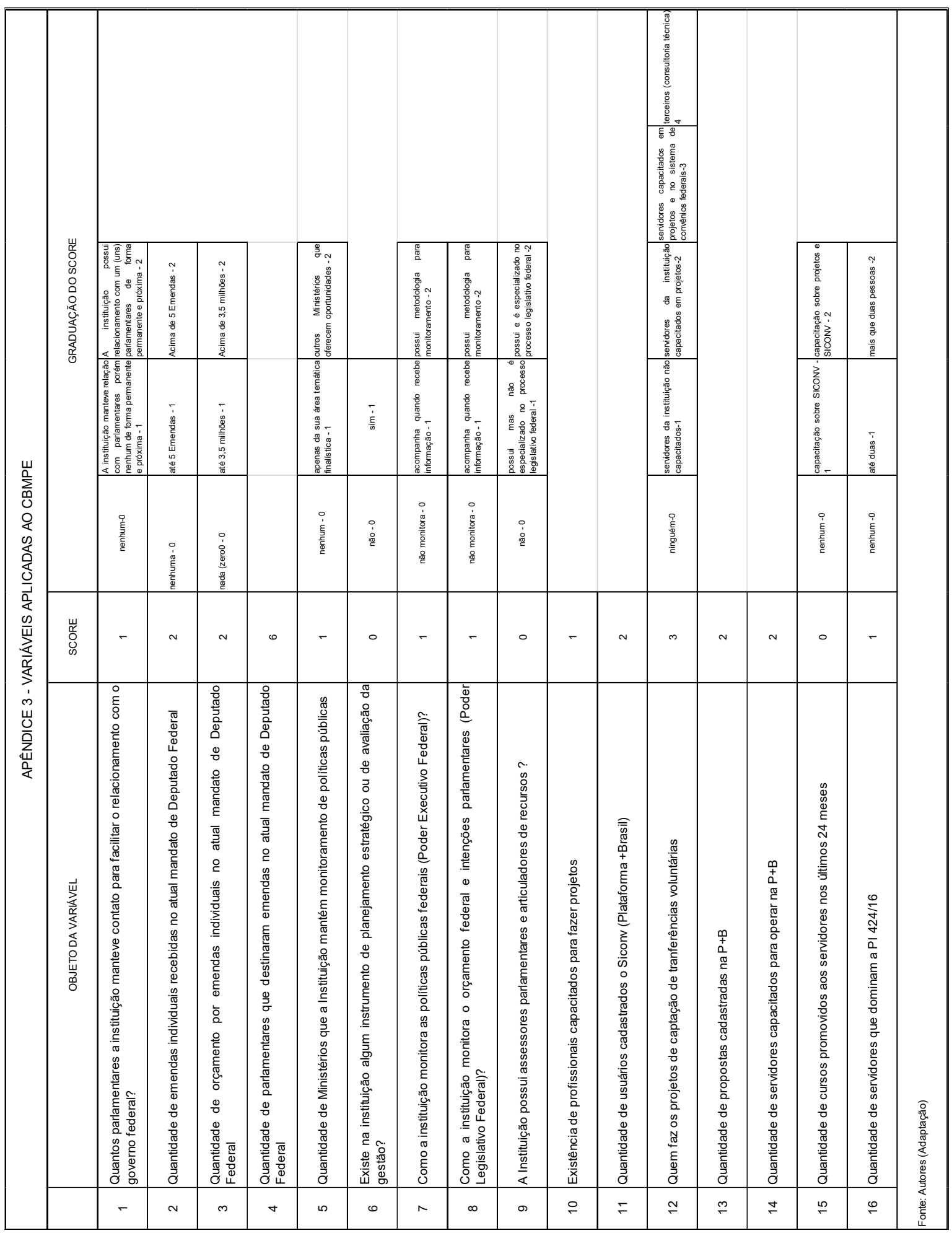


Revista FLAMMAE

Revista Científica do Corpo de Bombeiros Militar de Pernambuco

Artigo Publicado no Vol.06 N.17 - Edição Jul a Dez 2020 - ISSN 2359-4829

Versão on-line disponível em: http://www.revistaflammae.com

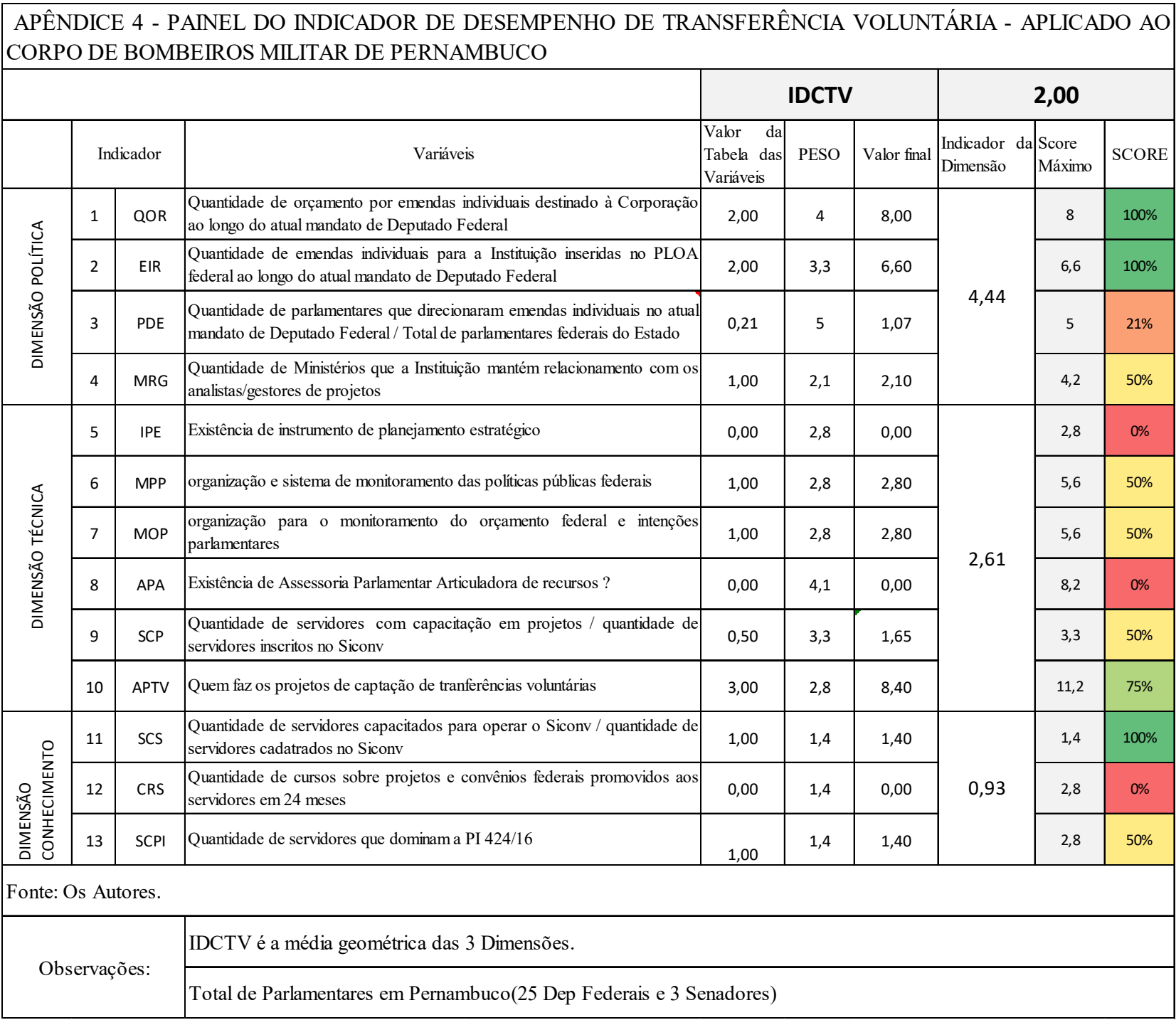

